Universidad de Lima

Escuela de Posgrado

Maestría en Tributación y Política Fiscal

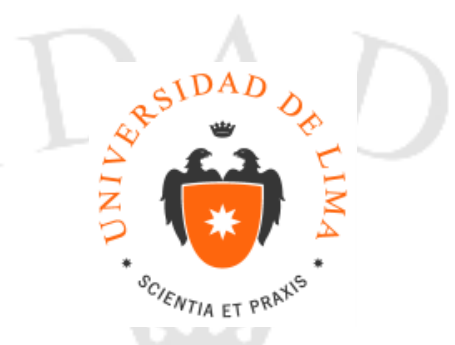

\title{
TRATAMIENTO TRIBUTARIO DE LOS COSTOS INDIRECTOS FIJOS INCURRIDOS EN PERIODOS DE VEDA EN EL SECTOR PESCA
}

Trabajo de investigación para optar el Grado Académico de Maestro en Tributación y Política Fiscal

Gerardo Arturo Agüero Luyo Código 20132458

\author{
Lima - Perú
}

Marzo 2016 


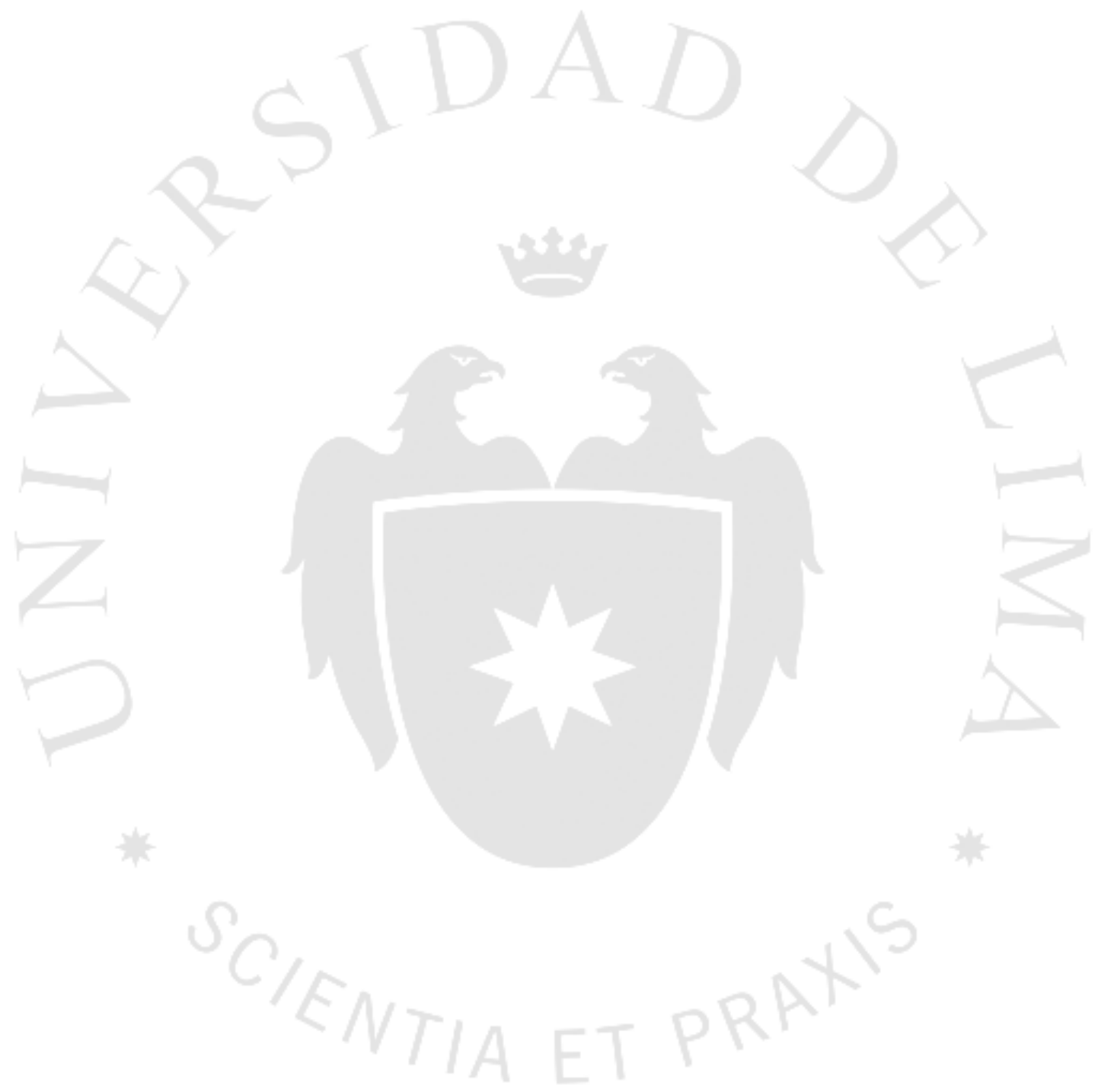




\section{TRATAMIENTO TRIBUTARIO DE LOS}

\section{COSTOS INDIRECTOS FIJOS INCURRIDOS EN PERIODOS DE VEDA EN EL SECTOR PESCA}




\section{TABLA DE CONTENIDOS}

INTRODUCCIÓN 1

1.1. Antecedentes del Sector Pesca y como contribuye la reforma del sector en el ejercicio 2008 para la asignación de los costos indirectos fijos al costo de

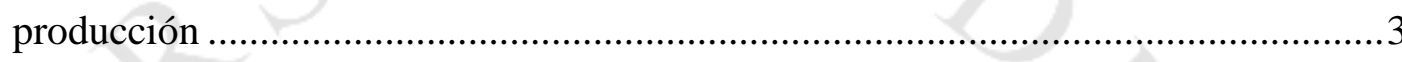

1.2. Aproximaciones sobre Costo y Gasto ..........................................................5

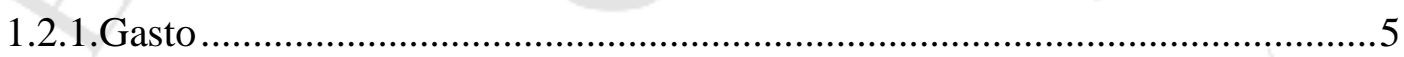

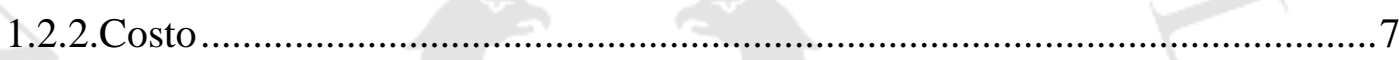

1.3.Tratamiento contable del costo de producción y su composición ...................... 7

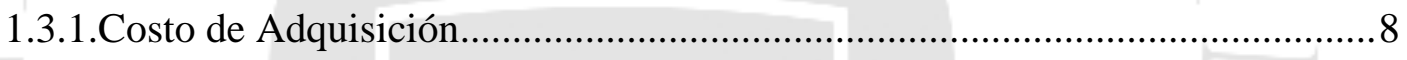

1.3.2.Costo de Transformación................................................................ 8

1.3.2.1.Costos indirectos fijos .............................................................

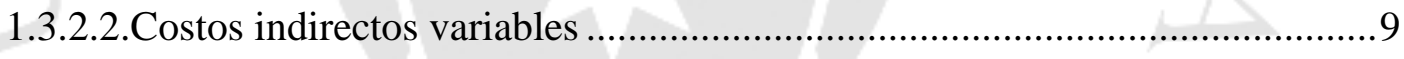

1.4.Principales conceptos relacionados con la determinación de la capacidad normal y los efectos que resultarían de su aplicación. ....................................... 10

1.5.Tratamiento contable de los costos indirectos fijos dentro de un proceso productivo constante bajo circunstancias normales......................................... 13

1.6.Tratamiento contable de los costos indirectos fijos incurridos en periodos de veda en el Sector Pesca ......................................................................... 14

\section{CAPÍTULO II: TRATAMIENTO TRIBUTARIO DE LOS COSTOS INDIRECTOS

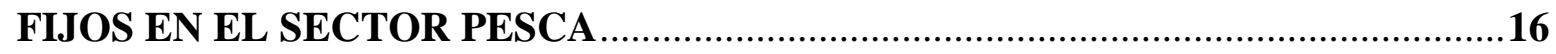

2.1. Tratamiento tributario del costo de las existencias y su composición...............16 
2.2.Vulneración del principio de reserva de ley y la aplicación supletoria de

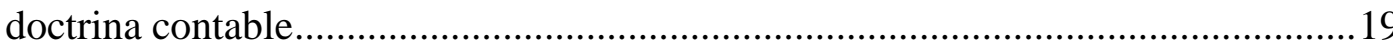

2.3. Consecuencias tributarias por reconocer directamente el íntegro de los costos de veda en resultados cuando se incurren.

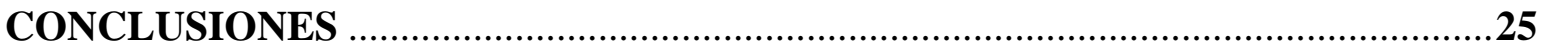

REFERENCIAS

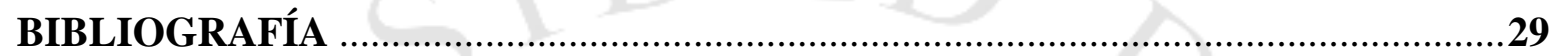




\section{INTRODUCCIÓN}

El sector pesquero que comprende las actividades de extracción y transformación de recursos hidrobiológicos tanto para el consumo humano directo (enlatado, fresco o congelado) e industrial (harina y aceite de pescado), es un elemento estratégico para la economía del Perú, principalmente por ser una importante fuente generadora de divisas después de la minería. Es por ello, que la Administración Tributaria en los últimos años ha venido incrementando las fiscalizaciones tributarias debido al alto nivel de impuestos recaudados en el sector.

Como consecuencias de las fiscalizaciones, han surgido discrepancias entre la Administración Tributaria y las empresas del sector pesquero debido a diferentes interpretaciones tanto de las normas tributarias y contables, motivo por el cual se han generado acotaciones tributarias que representan desembolsos importantes para cada empresa, generándoles así un perjuicio económico, lo cual es motivación para el desarrollo de la presente tesis.

En ese sentido, este trabajo está estructurado en dos capítulos, siendo que el primero aborda los antecedentes en el Sector Pesca y la Reforma del 2008 así como también el tratamiento contable del costo de producción y como está compuesto, la aplicación de la capacidad normal y la deducibilidad de los costos indirectos fijos en empresas del sector pesquero incurridos en periodos de veda, de tal forma que se pueda entender el tratamiento contable para la asignación de los costos indirectos fijos al costo de producción.

En el segundo capítulo explicaremos porque se está vulnerando el principio de reserva de ley al momento que la 1era DF 134-2004 nos remite a la NIC 2 para determinar que se debe entender por "gastos indirectos de fabricación o construcción", término que no ha sido definido por la LIR, asimismo, en el supuesto negado que dicha remisión sea válida nos remitiremos a la doctrina contable contenida en el marco conceptual para la preparación de los estados financieros y la NIC 2 para indicar cuál sería el tratamiento tributario correcto en la asignación de los costos indirectos fijos al costo de producción en épocas de veda y por último las consecuencias tributarias originadas hasta el ejercicio 2011 
si los costos indirectos fijos fueron enviados directamente a resultados cuando se incurrieron y como sería el tratamiento a partir del ejercicio 2012 producto del ordenamiento en el sector para la asignación de cuotas individuales por embarcación.

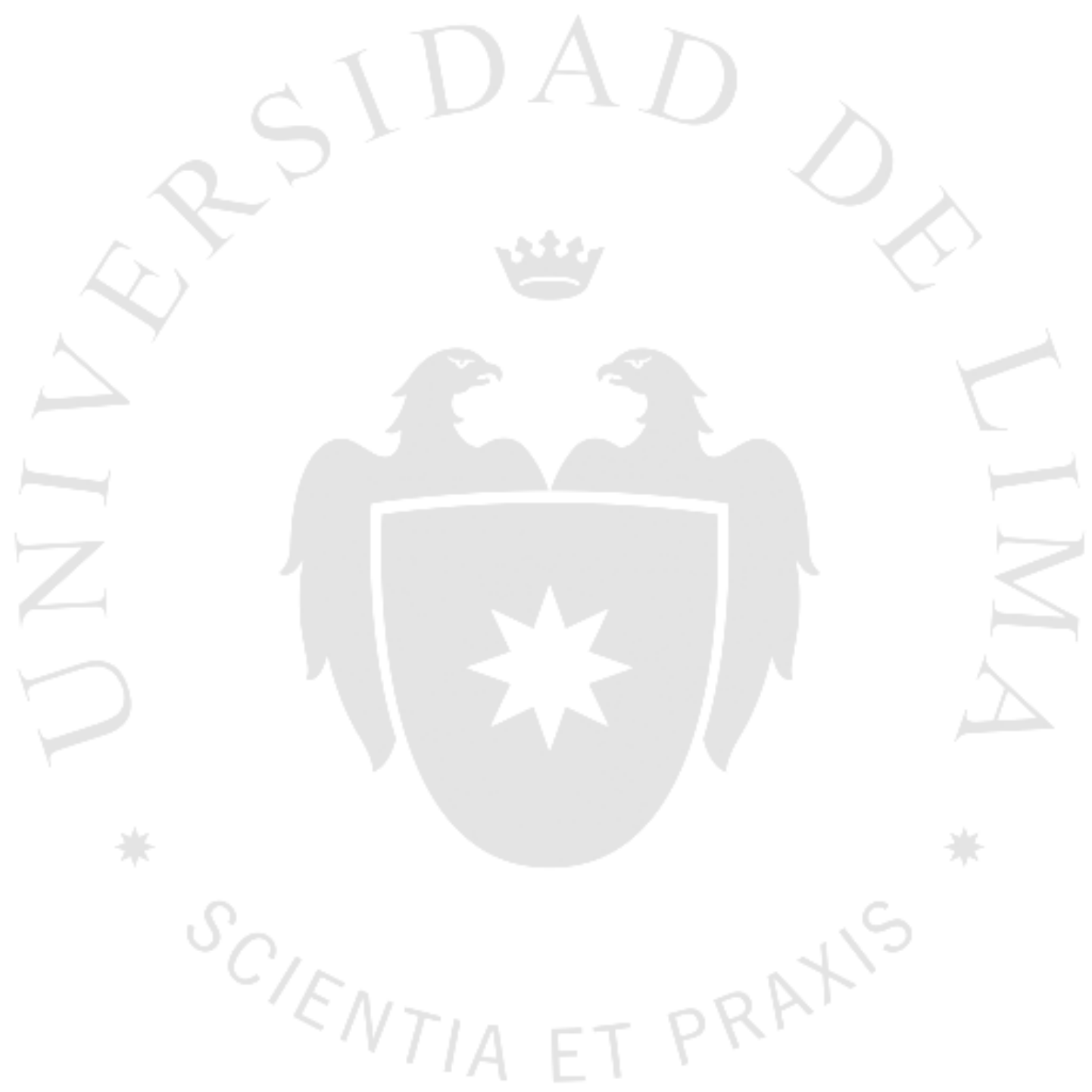




\section{CAPÍTULO I: ASPECTOS GENERALES DE LOS COSTOS}

\subsection{Antecedentes del Sector Pesca y como contribuye la reforma del sector en el ejercicio 2008 para la asignación de los costos indirectos fijos al costo de producción}

Las actividades del Sector Pesca (básicamente la extracción de recursos hidrobiológicos y su trasformación en harina y aceite de pescado, la elaboración de conservas de pescado y a la venta de pescado fresco y congelado tanto en el mercado nacional e internacional) están reguladas por el Decreto Ley $N^{\circ} 25977$, Ley General de Pesca, y su Reglamento, Decreto Supremo Nº 012 2001-PE. La administración y control de la actividad pesquera, en el ámbito nacional, está a cargo del Ministerio de la Producción (PRODUCE), entidad que hasta el ejercicio 2008 tuvo a su cargo el establecer la "Cuota Nacional de Pesca" en función de la biomasa disponible, aspecto que resultaba sumamente volátil, así como la fijación de los días de pesca y que también constituía un hecho imprevisible.

Esta situación generó una alta competencia entre empresas del sector, dado que todas las empresas querían pescar el máximo posible de la Cuota Nacional de Pesca en el menor tiempo posible, para ello, era necesario contar con un gran número de embarcaciones y plantas pesqueras, de tal manera poder explotar al máximo la Cuota Nacional de Pesca dentro del corto periodo asignado para la pesca.

Bajo este contexto, la premura del tiempo que tenían las empresas pesqueras en explotar al máximo la Cuota Nacional de Pesca, fue denominada la "carrera olímpica".

Es por ello, que el Gobierno Peruano con fecha 28 de junio de 2008 emitió el Decreto legislativo N 1084 “Ley sobre Límites Máximos de Captura por Embarcación”, y con fecha 12 de diciembre de 2008 emitió los Decretos Supremos Nº 021-2008 PRODUCE y 009-2009 PRODUCE, en base a estos dispositivos, se estableció un mecanismo de ordenamiento pesquero aplicable a la extracción del recurso Anchoveta destinada al Consumo Humano Indirecto (CHI), con el fin de mejorar las condiciones para su 
modernización y eficiencia; promover su desarrollo sostenido como fuente de alimentación empleo e ingresos y asegurar un aprovechamiento responsable de los recursos hidrobiológicos en armonía con la preservación del medio ambiente y la conservación de la biodiversidad.

En ese sentido, a partir del ejercicio 2009 se cambió el modelo de pesca, es decir, se pasó de cuotas nacionales máximas de captura anuales a por el de cuotas individuales por embarcación; este cambio generó que los periodos de extracción se extendieran.

Bajo los lineamientos del nuevo ordenamiento pesquero vigente desde el año 2009, se puede señalar como principales características las siguientes:

- Si bien es cierto, se mantiene la volatilidad en la biomasa, se reduce la incertidumbre dado que cada embarcación tiene una cuota asignada con lo que se puede planificar la pesca y se elimina el riesgo de pérdida de pesca en caso las embarcaciones no estén operativas.

- Este nuevo régimen hace posible calcular cómo impactaría la adquisición de embarcaciones en la capacidad de producción de las empresas pesqueras. ( cuota individual de pesca por estimación de cuota nacional).

- Incremento en los días de pesca que sumado a la cuota fija por embarcación elimina el riesgo en plantas de no producción debido a fallas en los equipos.

- Mayor planificación de producción en plantas.

Bajo lo expuesto, se puede observar las características en que ha operado el sector pesquero y fundamentalmente se podrá comprender la diferencia entre el régimen pesquero que predominó hasta el ejercicio 2008 y el vigente a partir del año 2009.

Hasta el 2008: Las empresas pesqueras operaron en periodos de alta volatilidad e incertidumbre en relación con la biomasa y operatividad de los activos, por ende, con la producción, por lo tanto las empresas pesqueras no estaban en la condición de estimar un nivel de capacidad normal.

Hasta el 2009: El ordenamiento pesquero basado en la Ley de Cuotas reduce la volatilidad de las variables internas de las empresas pesqueras, por lo que al haber una mayor predictibilidad en control, es factible determinar la capacidad normal. 


\subsection{Aproximaciones sobre Costo y Gasto}

Los conceptos de Costo y Gasto representan un egreso realizado por las empresas pesqueras con la finalidad de obtener un beneficio como fruto de la actividad económica, es decir, cuando los bienes del activo permanecen en el patrimonio manifestando su potencialidad económica de generar beneficios económicos en el futuro, su valor contable es reconocido como costo: pero cuando los mismos son utilizados para materializar tal expectativa, dicho valor asume la categoría de gasto del periodo en el que se produce tal beneficio.

A continuación, presentamos algunas definiciones y alcances de cada concepto:

\subsubsection{Gasto}

Para Giraldo (2006), "Los gastos son costos, los cuales han sido aplicados contra el ingreso, de un periodo determinado. Ejemplo: alquiler de local, energía eléctrica, consumo de agua, etc." (p. 222).

Por su parte, para Greco (2010) "el gasto consiste en la erogación no recuperable o el desembolso del dinero efectuado por diversos conceptos con el fin de cumplir objetivos de la empresa". (p. 243).

El Marco Conceptual también establece que existe una asociación muy estrecha entre la realización de un determinado desembolso y la generación de un activo, aunque uno y otro no tienen por qué coincidir necesariamente. Por tanto, si la entidad realiza un desembolso, este hecho puede suministrar evidencia de que pueden obtenerse beneficios económicos, pero no es una prueba concluyente de que se esté ante una partida que satisfaga la definición de activo, y que se convierta por tanto en una candidata para reconocimiento como tal en el balance. La definición de gastos incluye tanto las pérdidas como los gastos que surgen en las actividades ordinarias de la empresa.

De otro lado, la definición establecida en el párrafo 4.25 inciso b) del Marco Conceptual para la Información Financiera 2010, Gastos son los decrementos en los beneficios económicos, producidos a lo largo del periodo contable, en forma de salidas o disminuciones del valor de los activos, o bien por la generación o aumento de los pasivos 
que dan como resultado decrementos en el patrimonio, y no están relacionados con las distribuciones realizadas a los propietarios de este patrimonio.

Se reconoce un gasto en el Estado de Resultados cuando ha surgido un decremento en los beneficios económicos futuros, relacionado con un decremento en los activos o un incremento en los pasivos, y además el gasto puede medirse con fiabilidad. En definitiva, esto significa que tal reconocimiento del gasto ocurre simultáneamente con el reconocimiento de incrementos en las obligaciones o decrementos en los activos (por ejemplo, la acumulación o el devengo de salarios, o bien la depreciación del equipo).

En el párrafo 4.33 del Marco Conceptual para la Información Financiera 2010 se establece que la definición de Gastos incluye tanto las pérdidas como los gastos que surgen en las actividades ordinarias de la entidad. Entre los gastos de las actividades ordinarias se encuentran, por ejemplo el costo de ventas, los salarios y la depreciación. Usualmente, los gastos toman la forma de una salida o depreciación de activos, tales como efectivo y otras partidas equivalentes al efectivo, inventarios o propiedades, planta y equipo.

Es así que, los gastos se reconocen en el estado de resultados sobre la base de una asociación directa entre los costos incurridos y la obtención de partidas específicas de ingresos. Este proceso, al que se denomina comúnmente correlación de gastos con ingresos tal como lo establece el párrafo 4.50 del Marco Conceptual para la Información Financiera 2010, implica el reconocimiento simultáneo o combinado de unos y otros, si surgen directa $\mathrm{y}$ conjuntamente de las mismas transacciones $\mathrm{u}$ otros sucesos; por ejemplo, los diversos componentes de gasto que constituyen el costo de las mercancías vendidas se reconocen al mismo tiempo que el ingreso derivado de la venta de los bienes.

Por su parte el párrafo 4.51 del Marco Conceptual para la Información Financiera 2010 señala que cuando se espere que los beneficios económicos surjan a lo largo de varios períodos contables, y la asociación con los ingresos pueda determinarse únicamente de forma genérica o indirecta, los gastos se reconocen en el estado de resultados utilizando procedimientos sistemáticos y racionales de distribución. Esto es, a menudo, necesario para el reconocimiento de los gastos relacionados con el uso de activos tales como los que componen las propiedades, planta y equipo, así como la plusvalía, las patentes y las marcas; denominándose en estos casos al gasto correspondiente depreciación o amortización. Los 
procedimientos de distribución están diseñados a fin de que se reconozca el gasto en los períodos contables en que se consumen o expiran los beneficios económicos relacionados con estas partidas.

Del mismo modo, según el párrafo 4.52 del Marco Conceptual para la Información Financiera 2010, los gastos se reconocen inmediatamente dentro del estado de resultados cuando el desembolso correspondiente no produce beneficios económicos futuros, o cuando, y en la medida que, tales beneficios futuros no cumplen o dejan de cumplir las condiciones para su reconocimiento como activos en el balance.

\subsubsection{Costo}

El Diccionario de la Real Academia Española (2014) define al "costo como la cantidad que se da o se paga por algo". (p. 655).

Por su parte, Meigs, Williams, Haka y Bettner (2000) expresan que "el costo de un activo incluye todos los costos razonables y necesarios de llevar el activo a una ubicación apropiada y ponerlo en condición utilizable”. (p. 371)

De otro lado, Kholer (1970) señala que:

el costo es la erogación o desembolso en efectivo, en otros bienes, en acciones de capital o en servicio, o la obligación de incurrir en ellos, identificados con mercancía o servicios adquiridos o con cualquier pérdida incurrida, y medidos en función de dinero en efectivo pagado o por pagar o del valor de mercado de otros bienes, acciones de capital o servicios proporcionados en cambio. (p. 130)

Por lo tanto, se entiende por costo a los desembolsos que se realizan para la producción de un bien o servicio cuyo importe se espera recuperar con la venta de los productos o servicios que se generen.

\subsection{Tratamiento contable del costo de producción y su composición}

El Marco Conceptual para la preparación de los Estados Financieros establece la definición de activo, el cual lo define como un recurso controlado por la entidad como resultado de sucesos pasados, del que la entidad espera obtener, en el futuro, beneficios económicos. 
Asimismo, dicho Marco Conceptual establece que dentro del Estado de Resultados se reconoce directamente como gasto aquellos que no producen beneficios económicos futuros o cuando, y en la medida que, tales beneficios futuros no cumplen o dejan de cumplir las condiciones para su reconocimiento como activos en el balance.

De otro lado, la norma que prescribe el tratamiento contable de las Existencias es la Norma Internacional de Contabilidad 2 (en adelante, NIC 2) que define a los inventarios como activos:

a) Poseídos para ser vendidos en el curso normal de la operación

b) En proceso de producción con vistas a esa venta; o

c) En forma de materiales o suministros, para ser consumidos en el proceso de producción, o en la prestación de servicios.

La NIC 2 define también que el costo de las existencias debe incluir todos los costos derivados de su adquisición y transformación, asi como otros costos en los que se haya incurrido para darles su condición y ubicación actuales.

A continuación, se procederá a definir contablemente cada uno de los siguientes costos:

\subsubsection{Costo de Adquisición}

De acuerdo a lo señalado en el párrafo 11 de la NIC 2, el costo de adquisición de los inventarios comprenderá el precio de compra, los aranceles de importación y otros impuestos (que no sean recuperables posteriormente de las autoridades fiscales) y transporte, manejo y otros costos directamente atribuibles a la adquisición de mercaderías, materiales y servicios. Los descuentos comerciales, las rebajas y otras partidas similares se deducirán para determinar el costo de adquisición.

\subsubsection{Costo de Transformación}

El párrafo 12 de la NIC 2 establece que los "costos de transformación" de los inventarios (Existencias) comprenderán aquellos costos directamente relacionados con las unidades de producción, tales como la mano de obra directa. También comprenderán una distribución 
sistemática de los costos indirectos de producción, fijos o variables, en los que se haya incurrido para transformar las materias primas en productos terminados.

Por su parte, el párrafo 13 de la norma antes señalada, nos indica que el proceso distribución de los costos indirectos fijos a los costos de transformación se basará en la capacidad normal de trabajo de los medios de producción.

Capacidad normal es la producción que se espera conseguir en circunstancias normales, considerando el promedio de varios periodos o temporadas, y teniendo en cuenta la pérdida de capacidad que resulta de las operaciones previstas de mantenimiento.

El nivel real de producción puede usarse siempre que se aproxime a la capacidad normal. El monto de los costos indirectos fijos distribuido a cada unidad de producción no se debe incrementar como consecuencia de un nivel bajo de producción, ni por la existencia de capacidad ociosa.

Los costos indirectos no distribuidos se reconocerán como gastos del período en que han sido incurridos. En períodos de producción anormalmente alta, el importe de costos indirectos fijos que se distribuya a cada unidad producida se reducirá, de manera que no se valoren los inventarios por encima del costo.

Los costos indirectos variables se distribuirán a cada unidad de producción sobre la base del nivel real de uso de los medios de producción.

\subsubsection{Costos indirectos fijos}

Son costos indirectos fijos de producción los que permanecen relativamente constantes, independientemente del volumen de la producción, tales como la depreciación, el mantenimiento de la planta de producción y el costo de gestión y administración de ésta. Por su parte, Polimeni, Fabozzi y Adelberg (1994) señalan que "el total de los costos indirectos de fabricación fijos permanece constante dentro del rango relevante, independientemente de los cambios en los niveles de producción dentro de ese rango". (p.124)

\subsubsection{Costos indirectos variables}


Son costos indirectos variables de producción los que varían directamente, o casi directamente, con el volumen de la producción obtenida, tales como los materiales y la mano de obra indirecta.

De otro lado, Polimeni, Fabozzi y Adelberg (1994) señalan que:

el total de los costos indirectos de fabricación variables cambia en proporción directa al nivel de producción, dentro del rango relevante, que anteriormente se definió como el intervalo de actividad dentro del cual los costos fijos totales y los costos variables por unidad permanecen constantes; es decir, cuanto más grande sea el conjunto de unidades producidas, mayor será el total de costos indirectos de fabricación variables. Sin embargo, el costo indirecto de fabricación variable por unidad permanece constante a medida que la producción aumenta o disminuye. Por ejemplo, los materiales indirectos y la mano de obra indirecta. (p. 124)

\subsection{Principales conceptos relacionados con la determinación de la capacidad normal y los efectos que resultarían de su aplicación.}

Un concepto a que hace mención el párrafo 13 de la NIC 2 para determinar el costo de las existencias es el de "capacidad normal" que señala lo siguiente:

La distribución de los costos de producción indirectos fijos a los costos de transformación se basa en la capacidad normal de producción de la planta. "Capacidad normal" es la producción que se espera alcanzar en promedio en un número de períodos o temporadas bajo circunstancias normales, tomando en cuenta la pérdida de capacidad resultante de los planes de mantenimiento. El nivel actual de la producción puede ser usado si se aproxima a la capacidad normal. El monto de los costos indirectos fijos distribuido a cada unidad de producción no se debe incrementar como consecuencia de producción baja o de capacidad ociosa. Los costos indirectos que no se distribuyan se reconocen como gasto en el período en que se incurren. En períodos anormales de alta producción, el monto de los costos indirectos fijos que se distribuya a cada unidad producida se reduce de modo que las existencias no se valúen por encima de su costo. Los costos indirectos variables se distribuyen a cada unidad producida sobre la base del uso real de las instalaciones productivas.

Como se puede apreciar líneas arriba, la NIC 2 no especifica en detalle los factores que se deben considerar para establecer la capacidad normal del trabajo en los medios de 
producción y la forma cómo debe determinarse (sobre todo en circunstancias particulares como es el caso del Sector Pesca), hemos procedido a recurrir a determinada bibliografía especializada para que nos ayude a entender mejor este concepto.

En ese sentido, Horngren y Foster (1994), indican lo siguiente:

(...) la utilización de la capacidad normal es el nivel de uso de la capacidad que satisface la demanda promedio del cliente a lo largo de cierto periodo (por decir 2 a 3 años) que incluye factores de estacionalidad, ciclos y de tendencia (...). (p. 310)

Por su lado, Polimeni, Fabozzi y Adelberg (1994) indican lo siguiente:

... La capacidad productiva normal es utilizada por las empresas que consideran que el costo del producto debe basarse en un costo promedio que tenga en cuenta las interrupciones relacionadas con la producción y las fluctuaciones recurrentes en la demanda de los clientes. Suponiendo que todos los otros factores permanecen constantes, la capacidad productiva da por resultado unos costos del producto uniformes por unidad a través de diferentes periodos de tiempo.

El uso de la capacidad productiva normal elimina la posibilidad de manipulación del costo unitario del producto para niveles de producción que varían en forma deliberada. Es decir, debido a la presencia de los costos indirectos fijos, los aumentos deliberados en la producción disminuyen el costo unitario del producto, mientras que las disminuciones deliberadas en la producción aumentan el costo unitario.... (p. 127)

Como se puede apreciar, la capacidad normal está determinada por lo que se espera producir en base a la demanda de los clientes y pretende evitar distorsiones por situaciones anormales en la producción, evitándose así la manipulación de los costos unitarios por decisiones de la Gerencia.

Es por ello, que del análisis a la NIC 2 y doctrina contable se debe tener en cuenta lo siguiente:

En la teoría contable se hace referencia a la capacidad teórica, práctica y normal, por lo que pasaremos a definirlas e identificar las diferencias entre sí:

Capacidad teórica es la máxima capacidad a la que un proceso o una fábrica puede operar, asumiendo 24 horas de trabajo, durante 365 días, sin interrupción.

Capacidad práctica es igual a la capacidad disponible que se puede utilizar. Se determina restándole a la capacidad teórica los tiempos de interrupción inevitables de 
operación, como el tiempo de ajuste de la máquina, el mantenimiento preventivo, los días feriados, etc. Es decir, aquellos tiempos de interrupción inevitables de la operación.

Capacidad normal se refiere a la capacidad de utilización que satisface el promedio de la demanda de los clientes en el ciclo del negocio, considerando el promedio de varios periodos o temporadas, teniendo en cuenta la pérdida de capacidad que resulta de las operaciones previstas de mantenimiento. (Capacidad normal es menor a la capacidad práctica)

De otro lado, KPMG (2011) señala que "la distribución de los costes indirectos fijos se basa en la capacidad normal de las instalaciones de producción. Cualquier ineficiencia debe reconocerse en resultados, clasificándose como otros gastos, o, si una entidad clasifica sus gastos por función, dentro de la función apropiada.

Al determinar qué constituye la capacidad normal, deben considerarse los siguientes factores:

- la naturaleza del negocio, factores económicos, el saldo del ciclo de vida del producto y la fiabilidad de las previsiones;

- la capacidad y la utilización esperada de las instalaciones de producción, incluyendo las operaciones de mantenimiento y las interrupciones que se hayan planificado; y

- los niveles esperados de actividad a alcanzar de media a lo largo de una serie de períodos, ajustados por el efecto de fluctuaciones o circunstancias no usuales". (p. 505)

De otro lado, Rodríguez (2011) concluye que:

De la revisión de la doctrina contable y de la NIC 2 se debe concluir que la capacidad normal de planta es aquélla que permite satisfacer la demanda de los bienes producidos dentro del ciclo del negocio y que, a fin de determinarla, es necesario por lo menos tomar en cuenta la demanda y producción de, por lo menos, tres años representativos o de producción normal previos al ejercicio analizado. (p. 365)

Por lo tanto, las empresas pesqueras deberán definir el nivel de capacidad normal siempre y cuando se encuentren en la posibilidad de hacerlo, situación que no era posible hasta el ejercicio 2008 en el sector pesquero, debido a la volatilidad en la cuota de pesca como consecuencia de la biomasa y periodos de veda y por el alto riesgo de pérdida en la producción si alguno de los activos estaban inoperativos debido al corto periodo de pesca. 
Para aplicar la capacidad normal se debe contar con un promedio de producción, siendo la recomendación de diversos autores que se tome en cuenta el promedio de los 3 últimos años. Es por ello que, en principio, pese al cambio en el régimen pesquero introducido a partir del ejercicio 2009, las empresas pesqueras no podían aplicar el criterio de capacidad normal puesto que a esa fecha aún no existía un promedio de producción de tres años previos bajo este nuevo sistema, motivo por el cual recién a partir del ejercicio 2012 ya se encontraban en la posibilidad de establecer la capacidad normal y además porque ya era factible para las empresas pesqueras controlar razonablemente las variables externas.

\subsection{Tratamiento contable de los costos indirectos fijos dentro de un proceso productivo constante bajo circunstancias normales}

En principio, debemos tener en cuenta que proceso de producción se denomina al sistema dinámico constituido por un conjunto de procedimientos técnicos de modificación o transformación de materias primas, sean estas de origen animal, vegetal o mineral, y que puede valerse tanto de mano de obra humana, como de maquinaria o tecnología para la obtención de bienes y servicios. (significados.com)

De otro lado, el proceso productivo se desarrolla por etapas sucesivas que constan de una serie de operaciones interrelacionadas que deben desembocar en la consecución de un producto final cuyo valor, como resultado, se ha incrementado y está apto para su venta y consumo. Actividades que van desde la extracción de las materias primas hasta la puesta en venta del producto, puede decirse que forman parte del proceso de producción. (significados.com)

De igual forma, como proceso de producción industrial se denomina aquel que utiliza la industria y que comprende una serie de procedimientos, métodos y técnicas para el tratamiento, la transformación o la modificación de las materias primas, con intervención de mano de obra calificada y mediante el uso de maquinaria y tecnología, cuyo objetivo es la obtención de un bien o servicio de valor acrecentado para su consiguiente comercialización. 
No obstante ello, se puede definir a la producción normal como aquella que se obtiene bajo circunstancias normales, incluyendo las paralizaciones por mantenimiento de planta. (signficados.com)

En ese orden de ideas, los costos indirectos fijos incurridos en circunstancias normales formarán parte del costo de las existencias y su recupero se realizará a través del costo de ventas cuando se vendan las mismas, en épocas de veda los costos indirectos fijos que no se puedan asignar al costo de existencias por una baja producción o capacidad ociosa, serán enviados directamente al gasto puesto que de acuerdo a la NIC 2 el costo de existencias no puede verse sobrevalorado por la capacidad ociosa.

\subsection{Tratamiento contable de los costos indirectos fijos incurridos en periodos de veda en el Sector Pesca}

Los costos indirectos fijos (denominados costos de veda) y no producción básicamente están conformados por las cargas de personal (remuneraciones), depreciación de activos fijos, materiales y suministros, servicios, gastos administrativos, seguros y mantenimiento que se conocen fehacientemente, son medibles y en los cuales se han incurrido y que evidentemente no se encuentran relacionados con el proceso productivo, pues precisamente son costos incurridos en época de veda que no tienen relación con la producción ni con el proceso extractivo al estar prohibida la extracción en dichas épocas, por lo que claramente constituyen resultados devengados que deben reconocerse en el ejercicio conforme son incurridos.

De otro lado, el costo debe considerar la utilización efectiva de la planta en la producción y los costos variables que se han utilizado en ella; de forma tal que no se distorsione el valor real de los inventarios, lo que ocurriría si se reconocen como costo los gastos en que se incurren durante la veda.

El párrafo 48 de la NIC 16 - Propiedad, Planta y Equipo (en adelante NIC 16) establece que la depreciación siempre debe afectar resultados cuando no puede incluirse en el costo del activo; es decir, como se menciona en el párrafo 55 de la NIC 16; si la empresa opta por usar el método de línea recta (método reconocido para propósitos tributarios), un activo fijo siempre se deprecia y afecta resultados; lo que no ocurriría si se utiliza el método 
de unidades producidas, que implicaría que no se deprecia si no hay producción, que no es el caso.

Lo anterior está confirmado por el párrafo 56 de la NIC 16; que establece que la depreciación contiene no sólo el factor de uso en la producción, sino la pérdida de valor por diversos factores que implican su depreciación y reconocimiento de gasto, aun cuando no haya producción.

En la misma línea, es relevante tener presente la NIC 23 "Costos por Intereses" como norma que trata específicamente una situación similar, la cual establece que la capitalización de los costos por intereses debe ser suspendida durante los periodos en los que se interrumpe el desarrollo de actividades. Teniendo en cuenta que durante los periodos en los que están interrumpidas las actividades necesarias para preparar el activo para su uso deseado o para su venta no es posible que exista transformación alguna a menos que los activos requieran de un periodo de maduración para estar disponibles para la venta; se puede concluir claramente que los costos incurridos cuando se interrumpe el desarrollo de actividades (periodos de veda) no cumplen las condiciones para ser parte del costo del activo relacionado. El objetivo es evitar que, por motivo de una paralización (capacidad ociosa), los costos del activo se incrementen innecesariamente distorsionando su costo de producción.

Por lo tanto, en virtud del criterio de devengado y del principio de correlación de ingresos, las empresas pesqueras reconocen todos los gastos del período de veda, en el ejercicio en que incurrió; toda vez, que eran fiables y tenían certeza sobre éstos; además, porque dichos gastos no podían asociarse a costo de producto alguno ya que cuando éstos se incurrieron no había producción a qué imputarse.

De igual forma, estimar con precisión la capacidad normal de producción asume mayor relevancia cuando los costos fijos son importantes y/o los períodos ociosos no programados son extensos. Este factor es determinante en el caso de las empresas del sector pesquero para discriminar y reconocer apropiadamente a los costos de producción indirectos fijos. En efecto, los períodos de pesca al año permitidos a las empresas en Perú se han reducido de manera significativamente alarmante desde 230 días en 2002, hasta 176, 152, 102, 47, 47 y 48 días, respectivamente en los años 2003, 2004, 2005, 2006, 2007 y 
2008, evidenciando así la absoluta variabilidad de los periodos de veda y que reflejan de modo indirecto la "imprevisibilidad" de los días de pesca, siendo los periodos de veda sumamente variados con lo cual resulta imposible prever los periodos de veda que afectará a la producción.

Bajo este escenario, es evidente por ejemplo que si se asume que la entidad operó a capacidad normal en 2005, entonces en los años siguientes necesariamente operó por debajo de su capacidad normal. Como indicamos antes, en los períodos de baja producción, los costos de producción indirectos fijos no deben incrementar el costo de las existencias producidas. En consecuencia, la proporción de estos costos que correspondan a los períodos ociosos se deberá reconocer en los resultados; de lo contrario se incrementaría indebidamente el costo de las existencias.

Finalmente, caso contrario será si la producción es anormalmente alta, en la cual el costo indirecto fijo a distribuir a cada unidad de producción se reducirá y así los inventarios no serán valorados por encima del costo.

\section{CAPÍTULO II: TRATAMIENTO TRIBUTARIO DE LOS COSTOS INDIRECTOS FIJOS EN EL SECTOR PESCA}

\subsection{Tratamiento tributario del costo de las existencias y su composición}

Según el artículo $20^{\circ}$ de la LIR, la renta bruta está constituida por el conjunto de ingresos afectos al impuesto que se obtenga durante el ejercicio gravable. Cuando tales ingresos provengan de la enajenación de bienes, la renta bruta estará dada por la diferencia existente entre el ingreso neto total proveniente de dichas operaciones y el costo computable de los bienes enajenados. 
Asimismo, por costo computable de los bienes enajenados, se entenderá el costo de adquisición, producción o construcción, o, en su caso, el valor de ingreso al patrimonio o el valor en el último inventario determinado conforme a Ley, ajustados de acuerdo a las normas de ajuste por inflación con incidencia tributaria, según corresponda.

Para efectos de lo dispuesto líneas arriba, entiéndase por: Costo de Adquisición a la contraprestación pagada por el bien adquirido, incrementada en las mejoras incorporadas con carácter permanente y los gastos incurridos con motivo de su compra tales como: fletes, seguros, gastos de despacho, derechos aduaneros, instalación, montaje, comisiones normales, incluyendo las pagadas por el enajenante y otros gastos que resulten necesarios para colocar a los bienes en condiciones de ser usados, enajenados o aprovechados económicamente. En ningún caso los intereses formarán parte del costo de adquisición.

Costo de Producción o Construcción es el costo incurrido en la producción o construcción del bien, el cual a su vez comprende: los materiales directos utilizados, la mano de obra directa y los costos indirectos de fabricación o construcción.

Por su parte, el numeral 3 del inciso a) del artículo 11 del Reglamento de la LIR dispone que en el caso de la enajenación de bienes o transferencia de propiedad a cualquier título, el costo computable será el costo de adquisición o el costo de producción o construcción o el valor de ingreso al patrimonio o el valor en el último inventario, según corresponda. Para tales efectos se tendrá en cuenta que existe costo de producción o construcción, cuando el bien ha sido producido, construido o creado por el propio contribuyente.

Asimismo, el inciso j) del citado artículo establece que para la determinación del costo computable de los bienes o servicios, se tendrán en cuenta supletoriamente las normas que regulan el ajuste por inflación con incidencia tributaria, las Normas Internacionales de Contabilidad y los principios de contabilidad generalmente aceptados, en tanto no se opongan a lo dispuesto en la Ley y en su Reglamento.

Adicionalmente, el artículo 37 de la LIR dispone que a fin de determinar la renta neta de tercera categoría se deducirá de la renta bruta los gastos necesarios para mantener su fuente, así como los vinculados con la generación de ganancias de capital, en tanto su deducción no se encuentre expresamente prohibida por la LIR. 
Al respecto, se debe tener en consideración que a través de la Primera Disposición final del Decreto Supremo N ${ }^{\circ}$ 134-2004-EF, se precisó que la mención a "costos indirectos de fabricación o construcción" a que se refiere el numeral 2 del Artículo 20 de la LIR, corresponde al concepto de "gastos de producción indirectos" señalado en la Norma Internacional de Contabilidad relacionada con las Existencias (NIC 2).

En ese sentido, el concepto tributario de costo computable está referido al costo que debe tener un bien aunque la norma tributaria también utiliza este concepto para diferentes fines, por ejemplo cuando quiere determinar la renta bruta, en dicho caso la norma utiliza al costo computable de manera similar al Costo de Ventas o cuando quiere determinar la valuación de las existencias, el concepto se asemeja al de los costos de Inventarios.

Ahora bien, Medrano (2015) señala que "el costo computable es uno de los extremos que debe tomarse en cuenta cuando se trata de calcular la materia imponible derivada de la enajenación de bienes". (p. 42, 320-327)

Por lo tanto, la determinación de la Renta Bruta tributaria, según la LIR es la diferencia entre el ingreso afecto y el costo computable (sólo en el caso que la operación se halla tratado de bienes). En cambio, la Utilidad Bruta (contable) se obtiene de restar los ingresos menos el costo de ventas, independientemente se trate de bienes o servicios.

Para efectos del Impuesto a la Renta, el costo de una existencia se deducirá en el ejercicio en que se venda o se disponga de ella y además cumplir con el Principio de Causalidad.

Con relación al citado Principio de Causalidad, cabe señalar que el Tribunal Fiscal, en diversas resoluciones, ha delineado el criterio que ha asumido a los fines de interpretar la necesidad del gasto. Dicho criterio ha sido enunciado como sigue:

Que el principio de causalidad es la relación de necesidad que debe establecerse entre los gastos y la generación de renta o el mantenimiento de la fuente, noción que en nuestra legislación es de carácter amplio pues se permite las sustracciones de erogaciones que no guardan dicha relación de manera directa; no obstante ello el principio de causalidad debe ser atendido, por lo cual, para ser determinado deberá aplicarse criterios adicionales como que los gastos sean normales de acuerdo al giro de negocio o éstos mantengan cierta proporción con el volumen de las operaciones. (RTF $\mathrm{N}^{\circ}$ 710-2-99) 
Como puede verse, el Tribunal Fiscal ha descartado, en la apreciación de la necesidad del gasto, la tesis restrictiva según la cual sólo es deducible aquél gasto vinculado directamente a la generación de rentas gravadas con el impuesto. Más bien el Tribunal Fiscal se adscribe a las corrientes de deducciones de carácter amplio, para lo cual requiere "la normalidad", "la proporcionalidad" o la "razonabilidad" del gasto respecto de la actividad empresarial correspondiente; es decir, si el gasto es normal, proporcional o razonable a la actividad económica y aun cuando no genere una renta inmediata y directa, sino de modo indirecto o mediato, se cumple con el requisito de causalidad.

De la interpretación de las normas antes glosadas, tenemos que si bien las disposiciones del IR hacen referencia a los términos "costos de producción o de trasformación", no establecen que clase de gastos se deben encontrar dentro de dichos términos motivo por el cual en el siguiente punto se resolverá dicha interrogante.

\subsection{Vulneración del principio de reserva de ley y la aplicación supletoria de doctrina contable}

Partiendo de lo señalado en el punto anterior, tenemos que las normas que regulan el impuesto a la renta hacen una remisión directa a las Normas Internacionales de Contabilidad lo cual vulnera de manera flagrante el principio de reserva de ley consagrado en el artículo 74 de la Constitución Política del Perú que establece que "los tributos se crean, modifican o derogan, o se establece una exoneración, exclusivamente por ley o decreto legislativo en caso de delegación de facultades, salvo los aranceles y tasas, los cuales se regulan mediante decreto supremo". Asimismo, en el segundo párrafo establece de manera expresa que el Estado, al ejercer la potestad tributaria debe respetar el principio de reserva de ley.

El principio de reserva de ley en materia tributaria es un aspecto subsecuente de lo que la doctrina denomina potestad tributaria del Estado. Consiste en que los aspectos esenciales de los tributos que el Estado impone a las personas, deben ser aprobados por norma con rango de ley: ley o decreto legislativo, siempre que ocurra la delegación de facultades legislativas del Congreso al Ejecutivo, según el artículo 104 de la Constitución. 
$\mathrm{Al}$ respecto, el Tribunal Constitucional en su sentencia recaída en el Expediente $\mathrm{N}^{\circ}$ 2724-2007-AA/TC, con relación a la reserva de ley ha señalado lo siguiente (Fundamentos 12 y 13$)$ :

Acerca del principio de reserva de ley, este Tribunal Constitucional ha precisado que:

La reserva de ley en materia tributaria es en principio una reserva relativa. En tal sentido, es posible que la reserva de ley pueda admitir, excepcionalmente, derivaciones al reglamento, siempre y cuando los parámetros estén claramente establecidos en la propia Ley o norma con rango de Ley. Para ello se debe tomar en cuenta que el grado de concreción de sus elementos esenciales será máximo cuando regule los sujetos, el hecho imponible y la alícuota; será menor cuando se trate de otros elementos. En ningún caso, sin embargo, podrá aceptarse la entrega en blanco de facultades al Ejecutivo para regular la materia. (STC 0042-2005-AI/TC, fundamento 12, énfasis agregado).

De este modo, la regulación del hecho imponible en abstracto - que requiere la máxima observancia del principio de reserva de ley - debe comprender la alícuota, la descripción del hecho gravado (aspecto material), el sujeto acreedor y deudor del tributo (aspecto personal), el momento del nacimiento de la obligación tributaria (aspecto temporal), y el lugar de su acaecimiento (aspecto espacial), según ha señalado este Tribunal (STC 27622002-AA/TC y STC 3303-2003-AA/TC).

Como señala el Tribunal Constitucional en la sentencia citada, la reserva de ley en materia tributaria es relativa, es decir, permite que excepcionalmente algunos elementos esenciales del tributo puedan ser desarrollados por normas reglamentarias, siempre que éstas se encuentren subordinadas a la ley, justificándose ellos muchas veces en la complejidad técnica de la materia a regular, el carácter retributivo y no necesariamente contributivo de determinados tributos (contribuciones y tasas) y/o el dinamismo de la actividad a regular que exige respuestas oportunas en la regulación.

En ese sentido se ha pronunciado el Tribunal Constitucional en su sentencia recaída en el Expediente $\mathrm{N}^{\circ}$ 2762-2002-AA/TC, donde sostiene lo siguiente (Fundamento 13):

Así pues, en cualquier caso, nuestro texto constitucional habilitará remisiones de elementos esenciales del tributo a normas reglamentarias, única y excepcionalmente, cuando la ley misma establezca parámetros y límites de actuación a dicha norma, la razonabilidad así lo justifique, y se haya superado el análisis de proporcionalidad; es decir, cuando la referida 
remisión quede sustentada como una medida necesaria e ineludible. Sin embargo, en ninguno de estos casos podrá aceptarse la deslegalización de la materia tributaria, lo que significa la entrega abierta al Ejecutivo de facultades para determinarla.

En efecto, a partir de su propia doctrina jurisprudencial, el Tribunal Constitucional, en dos sentencias ya citadas anteriormente (STC $\mathrm{N}^{\circ}$ 3303-2003-AA/TC y 2762-2002-AA/TC) reconoció la validez constitucional de la derivación realizada por la ley en favor del reglamento para regular la alícuota del tributo, siempre y cuando los topes se encuentren establecidos en la ley, en un caso (aportes al OSINERG) validó dicha regulación por cuanto la ley establecía los topes, mientras que en el otro caso (alícuotas del ISC cuya regulación el artículo 61 de la Ley del IGV derivó al reglamento) declaró su inconstitucionalidad por carecer la ley de los parámetros necesarios, configurándose por tanto una remisión normativa en blanco.

Como se puede apreciar, el Tribunal Constitucional acepta la posibilidad de que el legislador pueda delegar la regulación de algunos elementos esenciales del tributo, ello sólo podrá realizarse a través de un Decreto Supremo, negando dicha posibilidad a una norma de inferior jerarquía. Así lo ha reconocido en la sentencia recaída en el Expediente $\mathrm{N}^{\circ} 3303$ 2003-AA/TC (fundamento 11):

Conforme ya lo hemos señalado en el Fundamento $\mathrm{N}^{\circ} 7$, supra, el principio de legalidad debe reforzarse en el caso de los elementos esenciales del tributo, como son los que conforman el hecho imponible en sentido abstracto, entre ellos el sujeto pasivo. Claro está que la remisión excepcional a un texto reglamentario atendiendo a la naturaleza del tributo y a criterios de razonabilidad, puede ser entendida únicamente si los parámetros se encuentran fijados en la ley; y esa excepcionalidad determina, a su vez, que la línea de frontera o el máximo grado de remisión sea la norma reglamentaria; por ello, no es posible admitir, bajo ninguna circunstancia, una norma de rango inferior, como lo es la Resolución del Consejo Directivo del OSINERG N²865-2001-OS/CD.

Bajo lo expuesto, el principio de reserva de ley y su carácter relativo, se debe indicar que si bien el Tribunal Constitucional acepta la posibilidad de que el legislador pueda delegar la regulación de algunos elementos esenciales del tributo, ello sólo podrá 
realizarse a través de un Decreto Supremo, negando dicha posibilidad a una norma de inferior jerarquía.

De otro lado, la Norma IX del Título Preliminar del Código Tributario autoriza la utilización de normas distintas a las tributarias y la aplicación, supletoria, de todos los métodos de interpretación admitidos en Derecho (Principios del Derecho Tributario, Principios del Derecho Administrativo y los Principios Generales del Derecho) siempre que no se les opongan ni la desnaturalicen.

Por su parte, Bravo (2003) dice:

Así, el resultado tributario no es sino el producto de efectuar determinados ajustes en el reconocimiento de ingresos y gastos, producto de diferencias en el tratamiento normativo. Pero, yendo más allá de dichas diferencias, debe advertirse que las normas del Impuesto a la Renta se soportan en diversos principios y postulados (devengado, registro, empresa en marcha, correlación de ingresos y gastos, precio de adquisición, realización) e instituciones y conceptos contables (activo, pasivo, costo computable, depreciación, provisiones, inventarios y contabilidad de costos, valuación de existencias, ajuste por inflación), a las que debe recurrirse a los efectos de interpretar adecuadamente los alcances de la norma tributaria (el subrayado es nuestro). (p.72)

Por lo tanto, en atención a lo establecido en la Norma IX del Título Preliminar del Código Tributario, nos remitiremos a la doctrina contable contenida en el marco conceptual para la preparación y presentación de los estados financieros y la NIC 2 como otro método de interpretación para determinar qué clase de gastos deben formar parte del costo de las existencias.

Finalmente, cabe indicar que esta posición también ha sido recogida por el Tribunal Fiscal en la Resolución N 1090-2-2008 que señala lo siguiente:

Que conforme con el artículo $20^{\circ}$ de la Ley del Impuesto a la Renta, la renta bruta, tratándose de la enajenación de bienes, está dada por la diferencia existente entre el ingreso neto total proveniente de tales operaciones y el costo computable de dichos bienes, constituido por el costo de adquisición o producción, la recurrente al ser una empresa productora debía considerar éste último costo para la determinación de la mencionada renta bruta. 
Que si bien nuestra normatividad impositiva no establece lo que debe entenderse por dicho costo de producción, es claro que el mismo se encuentra referido a los importes que fueron necesarios para la elaboración de los bienes, por lo que para efectuar su deducción a fin de determinar la renta bruta debe establecerse los elementos que lo conforman, para lo cual resulta pertinente recurrir a la contabilidad toda vez que a partir de la misma se realiza la determinación de la renta susceptible de gravamen para dicho tributo. (el subrayado es nuestro).

Es necesario mencionar que el criterio antes citado es reiterativo, lo cual se puede apreciar claramente de la Resolución del Tribunal Fiscal N 11981-2-2007 del 18 de diciembre de 2007, en la cual el Tribunal dispuso lo siguiente:

Este Tribunal ha señalado en diversas resoluciones tales como las Resoluciones $\mathrm{N}^{\circ} 06784$ 1-2002 y N01086-1-2003, que si bien nuestra normatividad impositiva no establece lo que debe entenderse por costo de producción, es claro que se encuentra referido a los importes que fueron necesarios para la elaboración de los bienes, por lo que para efectuar su deducción a fin de determinar la renta bruta debe establecerse los elementos que lo conforman, para lo cual resulta pertinente recurrir a la contabilidad, toda vez que a partir de ella se realiza la determinación de la renta susceptible de gravamen para dicho tributo.

\subsection{Consecuencias tributarias por reconocer directamente el íntegro de los costos de veda en resultados cuando se incurren.}

Como hemos venido indicando líneas arriba, producto de la reforma en la Ley de Pesca se puede establecer dos periodos claramente diferenciados, hasta el 2008 y a partir del 2009 hacia adelante.

La Administración Tributaria bajo una interpretación errónea, considera que como los periodos de veda son recurrentes año a año y constituyen interrupciones previsibles e inevitables en la producción, esta situación puede ser entendida como una circunstancia normal del giro del negocio y por lo tanto las empresas del sector pesquero si estaban en la posibilidad de determinar la capacidad normal de producción en cada ejercicio, en conclusión, en las fiscalizaciones actuales viene adicionando a la renta imponible todos los gastos de veda cargados a resultados. 
Asimismo, señala que no necesariamente tiene que haber producción para que los costos indirectos fijos de fabricación puedan ser imputados a los costos de las unidades producidas.

Por su lado, el Tribunal Fiscal a través de la Resolución $\mathrm{N}^{\circ}$ 4547-3-2004, confirma lo señalado por la Administración Tributaria quién argumentó que aun cuando los periodos de veda fueran más prolongados no califican como eventos extraordinarios, imprevisible e irresistible, pues responde a una situación propia de la actividad pesquera que todo agente económico relacionado con dicha actividad tiene la obligación de conocer. Caso distinto serán las vedas que no tienen una duración ordinaria sino que implican tiempos más prolongados y variados, en cuyo caso serán consideradas vedas de naturaleza extraordinaria.

Sin perjuicio de lo señalado en el párrafo anterior, consideramos que los periodos de veda son una circunstancia anormal de la producción puesto que depende de la condición de la biomasa de anchoveta así como también de las disposiciones que determine el PRODUCE para tales efectos.

En ese sentido, hasta el ejercicio 2011 no era factible determinar la capacidad normal de trabajo de las embarcaciones y de las plantas; motivo por el cual los costos indirectos no podrían distinguirse en función a la capacidad normal para su imputación a los costos de producción y debían ser reconocidos como gastos porque de lo contrario se estaría sobrevalorando los mismos y ello va en contra de lo que indica la NIC 2.

Nuestra posición ha sido admitida por el Tribunal Fiscal, pues en la Resolución $N^{\circ}$ 19413-1-2011 ha dejado establecido como criterio que aquéllas erogaciones que se encuentran destinadas a cubrir los costos de producción durante las épocas en las cuales existe una paralización de la producción, éstos deben ser enviados a los resultados del ejercicio y no deben formar parte del costo de producción o transformación de los productos. Es pertinente precisar que si bien en la mencionada Resolución el reparo ha sido confirmado, no es debido a que el Tribunal considere que de un análisis conceptual del tema materia de discusión tales erogaciones se debían enviar a los costos de los productos, si no que en aquél caso el contribuyente no acreditó cuál era la proporción que debía ir a gastos o al costo de los productos. 
Por lo tanto, si consideramos correcto que en los casos que la Administración Tributaria identifique gastos de veda cargados directamente en el costo de ventas, los adicione a la renta imponible si al cierre del ejercicio aún existía stock de existencias, puesto que lo correcto es asignar el costo de ventas en el ejercicio que se realice la venta (correlación de gastos con ingresos).

En conclusión, a partir del ejercicio 2012, como consecuencia del ordenamiento pesquero basado en cuotas individuales por embarcación, ya se puede determinar la capacidad normal tomando como referencia la producción de los últimos 3 ejercicios (2009, 2010 y 2011), con lo cual ya se puede conocer con claridad que parte de los costos de veda y no producción se deben asignar al costo de las existencias y que parte se deben cargar como gastos totalmente deducibles para fines del impuesto a la renta.

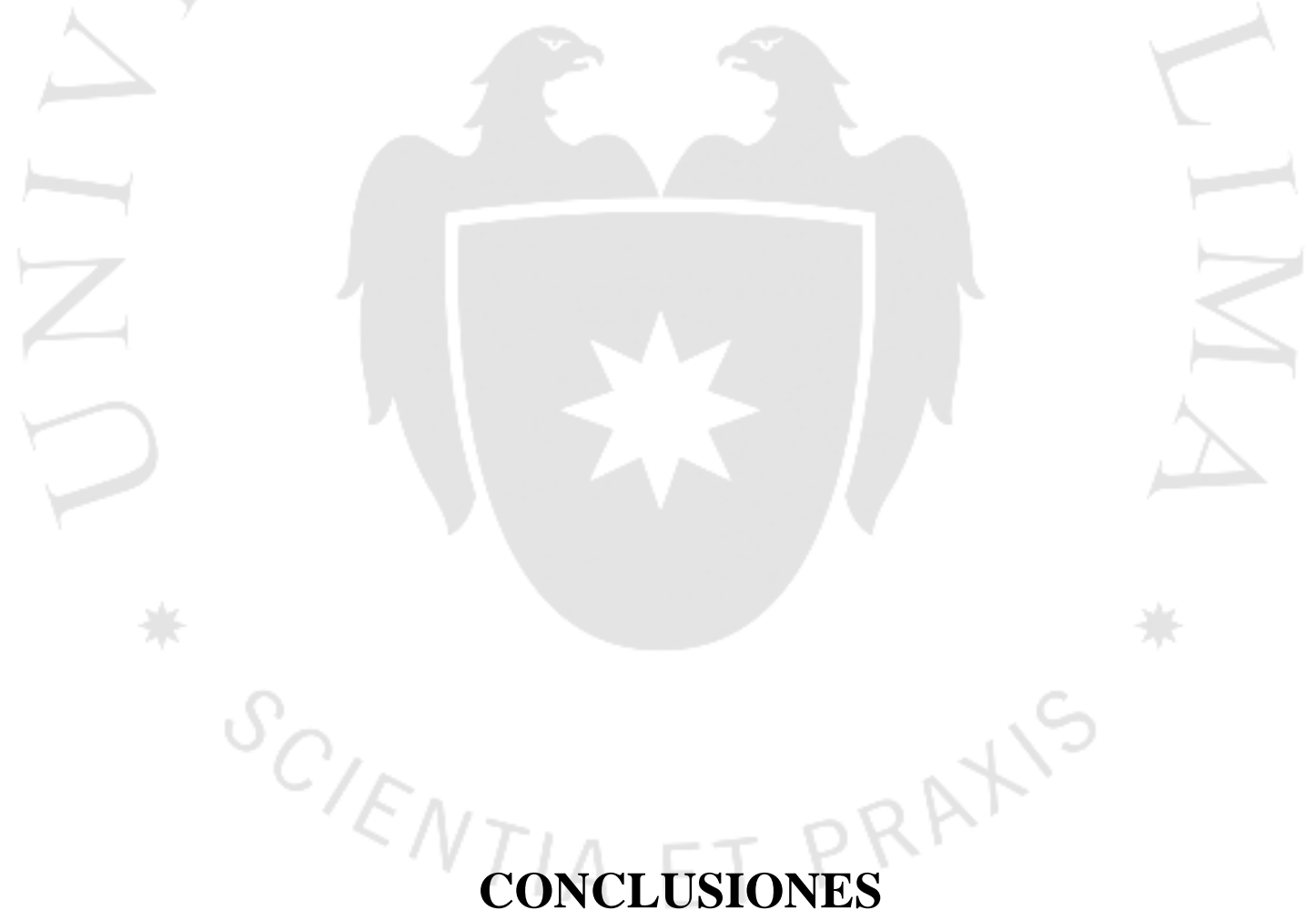

- La remisión directa de la 1era Disposición Final del Decreto Supremo N 134-2004-EF a la NIC 2 para la definición de los términos "costos indirectos de fabricación o construcción" que no han sido definidos en el numeral 2 del artículo 20 de la LIR, 
vulnera de manera flagrante el principio de reserva de ley consagrado en el artículo 74 de la Constitución Política del Perú al pretender regular la base imponible del impuesto a la renta, pese a tener rango de Decreto Supremo.

- La reserva de ley es una reserva relativa que admite excepcionalmente derivaciones al Reglamento, en tanto y en cuanto los parámetros estén establecidos en la Ley, asimismo, la Norma IX del Título Preliminar del CT establece que podrán aplicarse normas distintas a las tributarias siempre que no se les opongan ni las desnaturalicen, por lo tanto, nos remitiremos a la doctrina contable contenida en el marco conceptual para la preparación y presentación de los estados financieros y la NIC 2 como otro método de interpretación para desentrañar el sentido y alcances de las disposiciones tributarias vertidas tanto en la Ley como en su Reglamento.

- El establecimiento de límites de captura para cada embarcación genera consecuencias positivas en el sector pesquero, entre las cuales se distinguen una mejor programación de operaciones y mayor duración de las temporadas de pesca.

- Los periodos de veda son aspectos inevitables en las empresas pesqueras, estas no son previsibles dado que son controladas por un ente regulador externo (PRODUCE) y muestran alto grado de variabilidad anual histórica. Estas características hacen que los costos relacionados con épocas de veda no puedan ser considerados como parte del costo de capacidad normal ya que no generarían costos uniformes en los productos y no es posible su estimación y previsión en forma confiable.

- La capacidad normal está vinculada con la potencialidad de los activos fijos para producir bienes, siendo la capacidad instalada inactiva la que justifica que se cargue a resultados los costos de veda incurridos, por lo tanto, para determinar la capacidad normal se debe tomar en cuenta el promedio de los 3 últimos años de producción previos al ejercicio analizado.

- Los costos de veda y no producción no constituyen parte del costo de adquisición y transformación de las existencias dado que estos no forman parte del proceso productivo para transformar la materia prima en productos terminados, es decir, no contribuyen a poner a las existencias en su ubicación y condición actuales dado que son costos relacionados con temporadas en la que está prohibida la pesca de productos. 
- Para efectos de la determinación y liquidación del impuesto a la renta de los ejercicios gravables 2011 y anteriores, no se podía determinar la capacidad normal de los bienes que se utilizaban en la producción y en consecuencia se debían cargar directamente como gastos en los resultados del ejercicio en que se incurrieron.

- A partir del ejercicio 2012, como consecuencia del ordenamiento pesquero basado en cuotas individuales por embarcación, ya se puede determinar la capacidad normal tomando como referencia la producción de los últimos 3 ejercicios $(2009,2010$ y 2011), con lo cual ya se puede conocer con claridad que parte de los costos de veda y no producción se deben asignar al costo de las existencias y que parte se deben cargar como gastos totalmente deducibles para fines del impuesto a la renta.
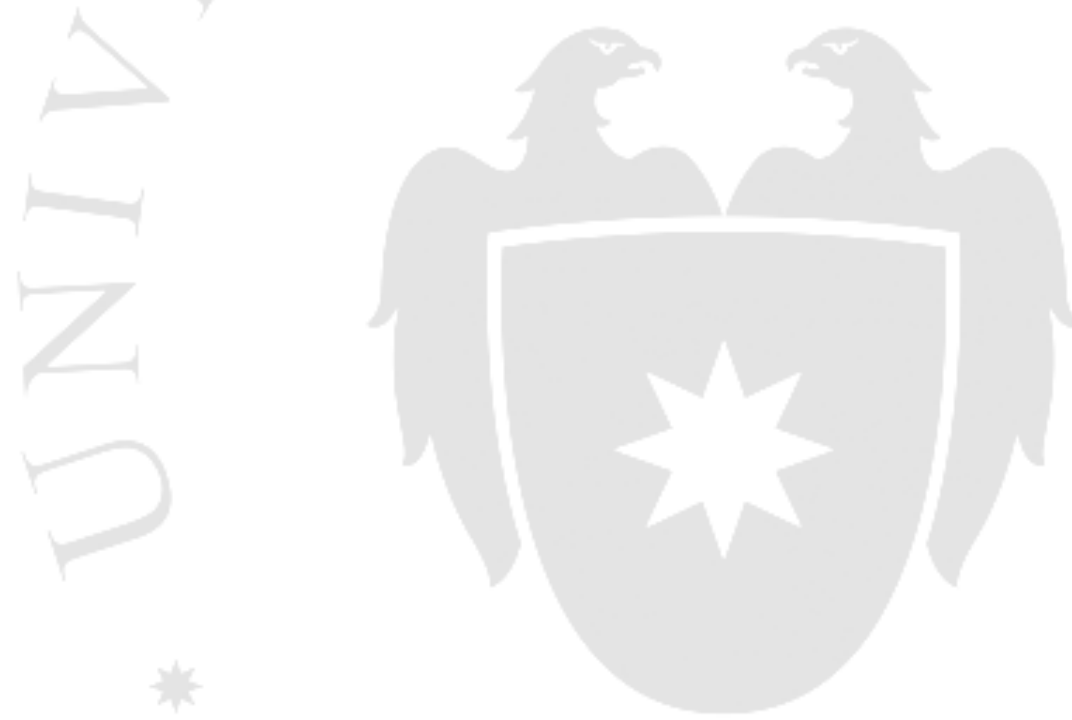

\section{REFERENCIAS}

"Proceso de Producción” (s.f.). En Significiados.com. Recuperado de:

https://www.significados.com/proceso-de-produccion/ 
Bravo, J. (junio del 2003). La Renta como materia imponible en el caso de actividades empresariales y su relación con la contabilidad, IFA, Cuadernos Tributarios, I (28). (I Foro Internacional de Tributación y Contabilidad) IPIDET -

Diccionario de la Lengua Española. (2014). (23 a ed.). Bogotá: Planeta Colombiana S.A.

Giraldo, D. (2006). Diccionario para Contadores. (1 ${ }^{\mathrm{a}}$ ed.) Perú: FECAT E.I.R.L.

Greco, O. (2010). Diccionario contable. (5 ${ }^{\mathrm{a}}$ ed.) Buenos Aires, Argentina: Valletta Ediciones.

Horngren, C. T. y Foster, G. (1994). Contabilidad de Costos. Un Enfoque Gerencial. (6 ${ }^{\mathrm{a}}$ ed.) México: Prentice Hall

Kohler, E. (1970). A Dictionary for Accountants. (4th Edition). New Jersey: Prentice-Hall.

KPMG (2011/12). Las NIIF Comentadas.

Medrano, H. (2015). Impuesto a la Renta y determinación del costo computable. IUS ET VERITAS

Meigs, R., Williams, J., Haka, S. Bettner, M. (2000). Contabilidad, La base para decisiones gerenciales. (11a Ed.) Colombia: McGraw Hill.

Polimeni, R., Fabozzi, F., Adelberg, A. (1994). Contabilidad de Costos (3a ed.). Santafé de Bogotá: McGraw-Hill Interamericana, S.A

Rodríguez, C. (mayo del 2014). El Costo de las Existencias y la Capacidad Normal de los medios de producción. II Foro de Tributación y Contabilidad. Precios de Transferencia y NIIF. (357-371) 


\section{BIBLIOGRAFÍA}

Aguilar Espinoza, H. (mayo del 2014). Tratamiento Contable de los inventarios de acuerdo a la NIC 2 y a la Jurisprudencia del Tribunal Fiscal. Asesor Empresarial, 31- 34.

Barfield, J., Raiborn, C. y Kinney, M. (2005). Contabilidad de Costos: tradiciones e innovaciones. ( $\left.5^{\mathrm{a}} \mathrm{ed}\right)$. México: International Thomson

Cárdenas N. Raúl. (2001). Contabilidad de Costos 1. México: IMCP

Cashin, James A. Y Polimen, Ralph. (1980) Contabilidad de Costos. Teoría y 375 problemas resueltos. Bogotá: McGraw - Hill.

Del Rio González, Cristóbal (1998). Costos I (17ª ed.) México: Editorial ECAFSA.

Ortega Pérez de León, Armando (1998). Contabilidad de Costos (6 $6^{\mathrm{a}}$ ed.) México: Editorial LIMUSA. 